\title{
IGREJA CATÓLICA E EDUCAÇÃO FEMININA: UMA OUTRA PERSPECTIVA ${ }^{1}$
}

\author{
Paula Leonardi ${ }^{2}$ \\ Faculdade de Educação USP/Fapesp \\ paulaleonardi@usp.br
}

\section{RESUMO:}

Partindo de um levantamento da vinda de Congregações estrangeiras para o Brasil e do estudo de duas Congregações francesas instaladas no país em 1906 e 1908, o presente artigo discute os investimentos da Igreja Católica na educação feminina. Mostrando que um grande número de Congregações femininas entrou no país no início do século XIX sem, no entanto, fundarem colégios, o artigo propõe a inversão da perspectiva tradicional da historiografia da educação: ao invés de começar o estudo pelos colégios católicos, iniciar o trabalho pela história das Congregações compreendendo seus percursos e os trabalhos ligados à educação não formal. Ao apontar diferentes percursos das congregações e ações em diferentes classes sociais, o artigo valoriza o trabalho com fontes internas ainda inexploradas para compreender a ação educativa dessas instituições.

Palavras-chaves: Educação feminina, Igreja católica e educação, Congregações católicas

\section{CATHOLIC CHURCH AND FEMININE EDUCATION: ANOTHER PERSPECTIVE}

\begin{abstract}
:
Beginning the analysis of the arrival of foreign Congregations to Brazil and of the study of two French Congregations installed at the country in 1906 and 1908, the present article discusses the investments of the Catholic Church in the feminine education. Showing that a great number of feminine Congregations came to the country in the beginning of the $19^{\text {th }}$ century without, however, found schools, the article proposes the inversion of the traditional perspective of the historiography of the education: instead of beginning the study for the Catholic schools, to begin the work for the history of the Congregations understanding their courses and the works with no formal education. Besides, it presents the need of the work with internal sources of the Congregations still unexplored.
\end{abstract}

Key-words: Feminine education, Catholic Church and education, Catholic Congregations

Em 1849 desembarcava no Rio de Janeiro um grupo composto por cinco mulheres e um padre vindo de Viena, Áustria. Sem falar o idioma e sem contato prévio com brasileiros, conseguiram abrigo no Convento da Ajuda onde foram acolhidos pelas Irmãs Concepcionistas. Este grupo fugia das revoluções de inspiração liberal que aconteciam na Europa e que, em muitos países, foram acompanhadas pelo avanço de idéias secularizantes que, por vezes, se traduziam em expulsão e perseguição de ordens e congregações religiosas $^{3}$. No Brasil, o grupo conseguiu a aprovação da Santa Sé para atuar como 
Congregação e passou a ser conhecido como Irmãs do Imaculado Coração de Maria. Doze anos depois de assumirem diferentes trabalhos, as irmãs conseguiram fundar seu próprio colégio no sul do país e, gradativamente, expandiram-se para outros Estados. (LEONARDI, 2002).

A história de Bárbara Maix, fundadora dessa Congregação, bem como o percurso da instituição, diferem do que comumente se observa na historiografia da educação: a história de colégios instalados no país sob outras condições, com prédios próprios e com uma clientela garantida pela aliança pré-estabelecida entre bispos - aqueles que fizeram o convite para a Congregação - e a oligarquia. Este é o caso, por exemplo, das Irmãs de São José de Chambery, que fundaram o Colégio Nossa Senhora do Patrocínio em Itu (MANOEL, 1996), ou dos três grandes colégios católicos femininos da cidade de São Paulo analisados por PEROSA (2005). Para uma congregação nova e de menor prestígio no interior da Igreja a instalação de um colégio foi somente um momento de sua história.

Este artigo aponta a vinda para o Brasil de outras congregações em situações semelhantes, discute a ação de duas congregações francesas no campo educacional e propõem a inversão da perspectiva historiográfica tradicional sobre Igreja Católica e educação.

\section{Missão ad gentes, exílio, feminização do catolicismo}

Em meados do século XIX iniciou-se um movimento de vinda de congregações estrangeiras para o Brasil. Três elementos se combinam para explicar este movimento: a busca pela retomada de espaços políticos por parte da Igreja Católica com o estímulo à missão ad gentes ${ }^{4}$, a perda de espaço das congregações docentes em alguns países como a França, e a feminização do catolicismo ocorrida durante o século XIX na Europa ${ }^{5}$. Em levantamento realizado junto aos arquivos da Cúria Metropolitana de São Paulo, através de um relatório do CERIS (Centro de Estudos Religiosos e Investigação Social) datado de 1965, foi possível quantificar esse movimento no Brasil ao longo das décadas ${ }^{6}$.

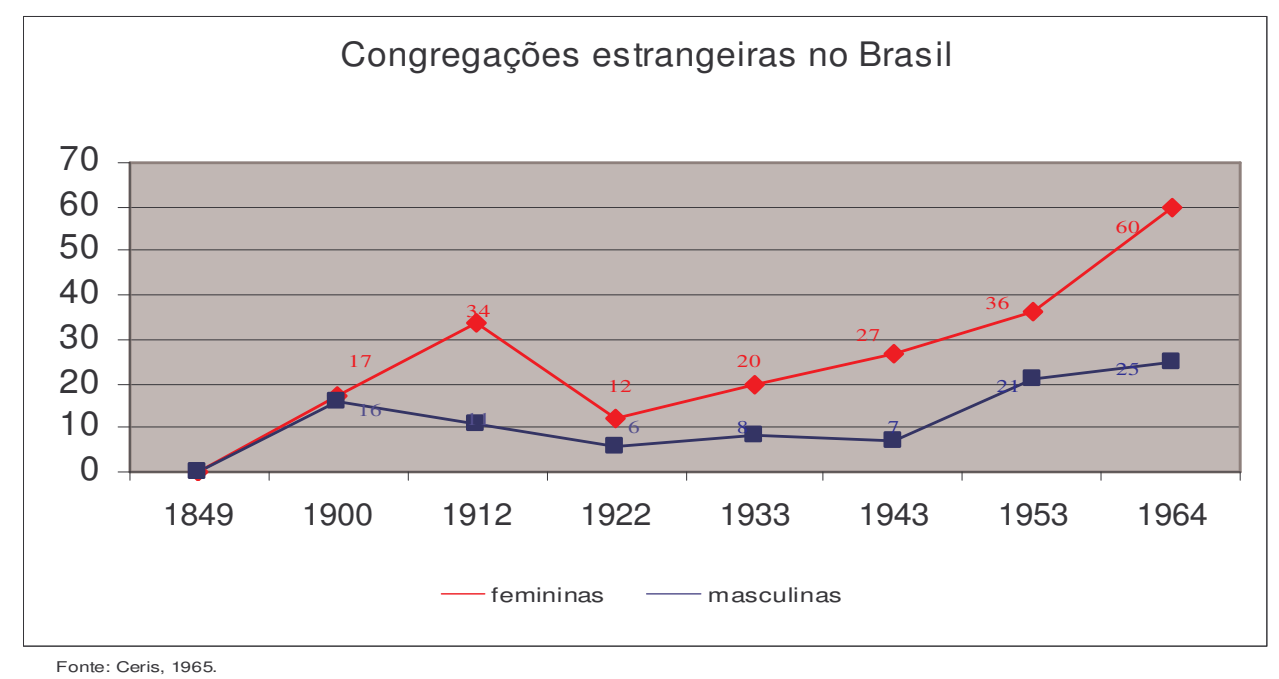

No Relatório não há dados de Congregações femininas estrangeiras que vieram para o Brasil antes de 1733. Embora existisse a presença religiosa feminina no Brasil no período colonial, Nunes (1997) aponta a ausência de conventos no Brasil até o século XVII, quando 
o convento de Santa Clara do Desterro na Bahia foi fundado (1677). As terras vizinhas, colonizadas por espanhóis, contavam já com 70 conventos quando o Desterro foi fundado no Brasil. As mulheres que desejavam ou que eram impelidas a entrar para a vida religiosa partiam para Portugal e, durante todo século XVIII, a situação não se modificou muito, afirma a autora. Esta afirmação é comprovada pelos dados do Relatório. Embora durante o século XVIII o movimento de vinda de Congregações estrangeiras masculinas cesse e se inicie o processo de vinda de Congregações femininas, o número é ínfimo: apenas 03. Para o século XIX, os números mudam: são 16 Congregações masculinas e 17 femininas. No entanto, é necessário ressaltar que a chegada de Congregações masculinas concentra-se nas últimas décadas do século XIX, enquanto que as femininas se dividiram ao longo de todo o século, ou seja, havia uma constância na entrada de Congregações femininas no Brasil a partir de meados do século XIX. Já no início do século XX, o movimento está claramente configurado: o número de Congregações femininas ultrapassava consideravelmente $\mathrm{O}$ número de masculinas, pois 34 femininas chegaram entre 1900 e 1912, e somente 11 masculinas, para o mesmo período. Assim, foi possível evidenciar que o movimento de vinda de Congregações estrangeiras para o Brasil foi mesmo iniciado no século XIX e teve seu ápice nas primeiras décadas do século XX.

Esses movimentos são explicados pela situação geral da Igreja e também pela situação política no Brasil. Ligada ao Estado pelo regime do padroado desde a colonização, a Igreja Católica era considerada oficial no país. Em troca, o poder temporal tinha o direito de nomear e indicar bispos e gerir os negócios religiosos. Assim, embora a ação evangelizadora junto aos índios tenha sido intensa no Brasil colônia, a Igreja não se estruturou como instituição separada do Estado: não tinha prédios, dioceses e nem pessoal distribuído por todo o território nacional. Desde 1550 até o fim do período monárquico o número de bispados em todo o Brasil era de apenas 12 (ROUX, 2008). Miceli (1988) já havia observado que esse território inexplorado era favorável para a expansão da Santa Sé. Para a Igreja, a América Latina era o future continent catholique (ROUX, 2008, p. 139).

Para retomar espaços perdidos com a progressiva secularização dos estados, ganhar novos territórios pouco ou inexplorados e centralizar o poder e a obediência ao papa, uma das ações da Santa Sé era estimular a missão ad gentes destinada a evangelizar/educar os povos ${ }^{7}$. A entrada de novas congregações no Brasil, sobretudo femininas, a partir de meados do século, pode ser explicada, em partes, por este incentivo papal. No Brasil Império, vigoravam decretos que impediam as antigas ordens presentes no país de receberem noviços e interferiam na entrada de novas congregações a fim de impedir a vinda de estrangeiros, especialmente religiosos (MOURA, 2000). Além disso, nenhuma nova diocese foi criada no país após 1854 e essas ações do governo explicam a entrada reduzida de congregações estrangeiras.

Por outro lado, os números crescem ao se aproximar a data da proclamação da República e este crescimento avança para as primeiras décadas do século XX. Apesar da ruptura com o regime de padroado e da nova constituição proclamar o estado laico, o aumento da vinda dessas congregações atesta uma aliança velada entre governo e Igreja para preencher lacunas que o poder temporal não conseguia cobrir. A educação, tomada nos primeiros anos da República como solução para todos os males sociais e para o desenvolvimento do sentimento de nacionalidade não foi desenvolvida pelo estado. Um sistema nacional de educação estatal foi organizado tardiamente em nosso país. Como não havia quadros de professores suficientes, as ordens e congregações supriam essa ausência atendendo a diferentes grupos sociais e não somente a elite. Daí a liberação, se não explícita, ao menos condescendente, da ação de congregações estrangeiras no território brasileiro. Era preciso bem educar especialmente a mulher, disseminadora de moral e 
ideais dentro dos lares e educadora por excelência (LEONARDI, 2004; ROSSI \& INÁCIO FILHO, 2006).

De sua parte, a Igreja Católica precisava se federalizar no país (MICELI, 1988), construir prédios e formar pessoal para seus quadros internos. A presença do clero estrangeiro e a nomeação de bispos ultramontanos garantiam à Santa Sé o desenvolvimento da política ultramontana no país. Para Beozzo (1980), a romanização significou também uma europeização do clero, ao procurar introduzir no país Ordens e Congregações européias que restituíssem a hierarquia e submissão a Roma, combatessem os ideais iluministas e que trouxessem novas devoções a fim de combater o catolicismo popular não hierárquico e pouco ligado aos cultos da Igreja e aos sacramentos. Entre 1890 e 1930 foram criadas 56 dioceses, 18 prelazias e 3 prefeituras apostólicas (MICELI, 1988). Para isso, foram nomeados 100 bispos e as principais concentrações foram no nordeste, São Paulo e Minas Gerais. A ação das congregações em diversos seguimentos também garantia o recrutamento. Embora o espaço privilegiado para isso fosse a educação em internatos (LEONARDI, 2009), procurava-se atingir todos os grupos sociais, até mesmo aqueles que não poderiam matricular seus filhos e filhas em internatos. Há inúmeros exemplos em monografias de incentivos governamentais, doações de terrenos e subvenções a escolas confessionais ao longo de toda a República.

As instituições que vieram para o país entre 1880 e 1912, se concentravam nos Estados de Minas Gerais, Rio de Janeiro e São Paulo, o que se explica pelo desenvolvimento econômico e político destas regiões no período. Tomando o caso do Estado de São Paulo, a maior concentração era de Congregações francesas e italianas, dentre as quais algumas permanecem desconhecidas da historiografia da educação já que fundaram seus colégios somente em meados do século XX (LEONARDI, 2008) ${ }^{8}$.

Além dos investimentos da Igreja em educação através de incentivos à missão $a d$ gentes, e da aliança velada entre governo e Igreja no Brasil, há situações específicas nos países de origem dessas congregações e a feminização do catolicismo que também explicam a grande entrada de congregações femininas no Brasil.

Tomando o caso das congregações francesas, a feminização do catolicismo naquele país traduzia-se pela feminização da prática e pela entrada de mulheres em grande quantidade para a vida religiosa, temas explorados por Langlois (1984). A feminização revelava-se em um modelo de organização que se tornou dominante durante o século XIX na França, a saber, as congregações com superiora geral. Essas instituições tinham a possibilidade de se desenvolverem em diversos lugares, mas sempre ligadas à superiora geral e a uma sede, chamada Casa Geral ou Casa Mãe, de onde emanavam todas as ordens e decisões sobre os rumos da Congregação: recrutamento, trabalhos assumidos, compras de prédios etc. As superioras administravam, portanto, espécies de empresas, com suas sucursais espalhadas por todo o país e, mais tarde, espalhadas também pelo exterior, mantendo sempre a centralidade do governo. Além desse aspecto, seus membros tinham uma característica particular em relação às antigas ordens: dirigiam-se para uma vida ativa como professoras ou enfermeiras ${ }^{9}$. Muitas das congregações nascidas durante o século XIX desenvolveram-se a partir de associações leigas, como as confrarias, irmandades e ordens terceiras (LANGLOIS, 1984). Tratava-se da reunião de um grupo de pessoas que se devotavam a algumas práticas como a freqüência aos sacramentos, reuniões para orações e ações caridosas de assistência a necessitados. A aceitação da Santa Sé a fundação de congregações femininas com superiora geral também se inseria dentro das estratégias ultramontanas de difusão da religião através das mulheres.

Durante um período quase ininterrupto de crescimento na França (1800-1880), 20\% dessas Congregações voltou-se para a internacionalização, fosse por esforço missionário 
impulsionado pela Santa Sé, por simples difusão fronteiriça com outros países, ou ainda pela criação de Congregações destinadas a tornarem-se internacionais (LANGLOIS in: CORBIN, 1984). Para as Congregações femininas, isso se traduzia primeiro em uma abertura para o exterior daquelas já consolidadas na França.

Aliado a esse processo há também o caso daquelas que deixavam o país como exiladas porque partiram não para expandirem suas comunidades, mas para abrirem novas possibilidades de manutenção da instituição, já que sua sobrevivência estava ameaçada em seu país de origem (CABANEL \& DURAND, 2005). Desde as leis sobre o ensino, instauradas na Jules Ferry (1880-84), as Congregações de professoras estavam ameaçadas de perderem suas escolas. Essas leis delimitavam o campo de ação das instituições, obrigando-as a solicitarem uma autorização junto ao ministério de Cultos para manterem o funcionamento de suas escolas ${ }^{10}$. Embora sua aplicação tenha sido branda, no início do século XX duas outras leis foram publicadas em 1901 (que em seu artigo 14 retirava das Congregações não autorizadas o direito de ensinar) e em 1903 (Loi relative à la supression de l'enseignement congréganiste, que proibia qualquer tipo de ensino pelas Congregações na França). A primeira ratificava as obrigações anteriormente exigidas e, a segunda, proibia qualquer tipo de ensino oferecido por Congregações católicas. Foi nesse contexto que muitas instituições enviaram irmãs, irmãos e padres para outros países.

A situação das Congregações francesas docentes no início do século XIX não era de todo desconhecida dos padres brasileiros. Logo após sua chegada ao Brasil em 1902 como núncio apostólico, Monsenhor Giulio Tonti enviou circular aos bispos brasileiros explicando a situação de diversas Congregações francesas ameaçadas em função do fechamento de suas escolas e solicitando a acolhida destes religiosos (CABANEL \& DURAND, 2005). Antes mesmo de o Brasil ser um país de refúgio para as Congregações como a Nossa Senhora do Calvário, o papa Leão XIII, tomando ciência da situação da América Latina no Concílio Plenário de 1899, já havia pedido em circular que as Congregações européias fizessem do continente americano uma das prioridades de seu apostolado (LA BELLA in CABANEL \& DURAND, 2005). A situação da Igreja no Brasil também inspirava os cuidados da Santa Sé, que pretendia ter no país um clero obediente às suas determinações.

Essas análises endereçam para questões sobre os percursos dessas congregações. Ao iniciar o estudo pelas congregações e não por seus colégios, é possível perceber que as congregações femininas francesas se dedicavam a outras atividades que não só a educação de elites em colégios, a qual são comumente associadas.

\section{Olhar por dentro: as Calvarianas e a Sagrada Família}

Colocando em relação duas pesquisas que se iniciaram pela história dos colégios, é possível observar que o status das congregações e ordens no interior da Igreja lhes conferia possibilidades para alianças com grupos dirigentes ou não. Duas situações diferentes ilustram esta afirmação. Trata-se da instalação do Colégio Puríssimo em Rio Claro (LEONARDI, 2002) e do Colégio Sagrado Coração de Jesus em Campinas (LEONARDI, 2008), ambos no Estado de São Paulo; e o caso do Ginásio Catarinense em Florianópolis, Santa Catarina (DALLABRIDA, 2001). Na primeira situação, duas congregações femininas de menor relevo no interior da Igreja, que vieram para o Brasil na condição de exiladas $^{11}$ e que assumiram trabalhos diversos antes de fundarem seus próprios colégios e desenvolverem-se, estabelecendo contatos com padres ultramontanos seguindo suas 
diretrizes em alianças com grupos dirigentes. No caso do Ginásio Catarinense, tratava-se de encerrar os trabalhos de uma instituição pública, passando-a para as mãos da Companhia de Jesus, ao mesmo tempo em que o ginásio seria parcialmente subvencionado pelo governo. Se a instalação de estabelecimentos de ensino secundários nas capitais de grandes Estados fazia parte da articulação da Igreja no início da República (DALLABRIDA, 2001), as alianças aconteceram, mas de formas diferenciadas. Para os jesuítas, o fato de pertencerem a uma ordem que, embora já tivesse vivido a perseguição, gozava de prestígio na Igreja, facilitava as negociações e o desenvolvimento de seus trabalhos. Para as Irmãs do Imaculado Coração doze anos se passaram desde sua chegada ao Brasil até a instalação do colégio próprio. Para as Calvarianas, o colégio foi fundado um ano após trabalhem como enfermeiras e lavadeiras em um seminário.

Estes especialistas, padres e freiras, enviados para outros países e encarregados da gestão dos bens de salvação (BOURDIEU, 1999), salvavam de diferentes formas, de acordo com o status de suas Congregações no interior da Igreja e de acordo com as alianças políticas que logravam estabelecer. Observar o percurso dessas congregações através de documentos internos oferece a possibilidade de compreender os caminhos por elas escolhidos, a adaptação em outro país, sua posição na hierarquia da Igreja e com quais grupos sociais se relacionavam em um olhar por dentro das instituições.

As duas congregações aqui colocadas em foco têm suas origens na França durante a segunda metade do século XIX, o período da chamada feminização do catolicismo. A Congregação das Irmãs da Sagrada Família de Bordeaux considera o ano de 1820 como aquele de sua fundação (na cidade de Bordeaux) e instalou-se no Brasil em 1908. A Congregação das Irmãs de Nossa Senhora do Calvário (Calvarianas), considera o ano de 1833 para comemorar sua fundação, fixou-se no Brasil em 1906. Essas instituições têm diferenças significativas em suas estruturas que, em última instância determinaram os motivos da saída da França e influenciaram, em partes, seus percursos no Brasil.

Dentre as congregações francesas fundadas ao longo do século XIX na França, a Sagrada Família de Bordeaux chama a atenção por sua diversidade. Esta Congregação oferecia a seus membros diferentes possibilidades de participação. Tendo como exemplo Jesus, Maria e José, a instituição pretendia formar uma família composta por membros desiguais, mas com um mesmo coração e uma mesma alma, assim como na Igreja dos primeiros cristãos, afirmava as Regras (1851), escritas por padre Noailles, considerado o fundador desta Congregação. A instituição apresentava, em sua estrutura, a presença de membros leigos, membros consagrados que professavam votos e viviam em comunidades ou que professavam votos e viviam em famílias, trabalhando e tendo uma vida normal como quaisquer outras pessoas. A complexa formação da Sagrada Família era explicada por Noailles como a imagem de uma árvore: 


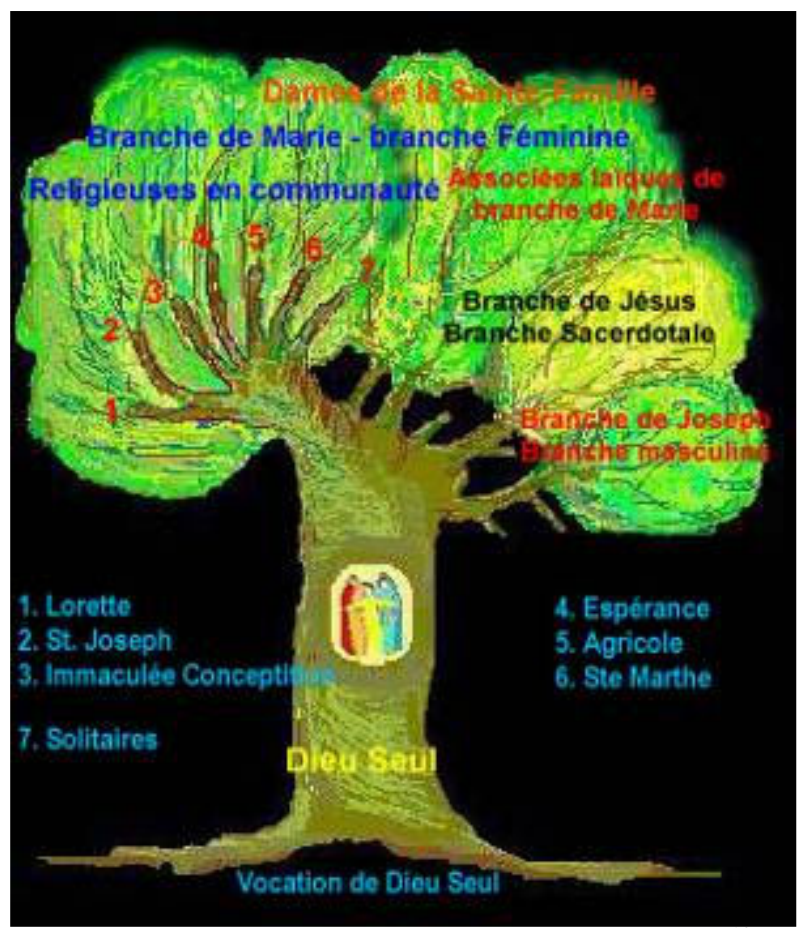

Imagem do site da Sagrada Família de Bordeaux ${ }^{12}$

Havia quatro ramos principais em 1851 assim denominados: Jesus (formado por homens que pertenciam à classe eclesiástica), São José (homens fora da classe eclesiástica), Maria (mulheres admitidas) e Filhas de Deus Só (mulheres que viviam isoladamente se submetendo a regras próprias e aceitando, indiferentemente, todas as obras ou atividades propostas pela Associação - estas eram as congreganistas ou Irmãs). Dentro de cada ramo ainda havia subdivisões de tarefas, como por exemplo, no ramo de Maria: grupo do Zelo (responsáveis pela extensão das obras e avanço espiritual dos membros, conversão de pecadores, cuidado de doentes e pobres, etc), grupo do Trabalho (dedicado à direção geral do temporal de toda a associação, ao bem estar da classe operária para a perfeição dos trabalhos manuais e boa gestão dos produtos), grupo do Ensino (dedicado à educação da juventude). Posteriormente, e de acordo com as demandas, foram criados os outros ramos (numerados em azul nas laterais do tronco da árvore) que se referem somente às Irmãs e não ao ramo leigo.

Dentre essas pessoas que se reuniam na Associação, ocasionalmente distinguiamse, como narrou Noailles, aquelas que optavam pelos hábitos restritos, vivendo piedosamente, retiradas em comunidades. Essas pessoas constituíam a Congregação ${ }^{13}$. Dentro da Congregação, a estrutura foi se subdividindo para atender às demandas das diferentes localidades nas quais se instalavam. A partir das Regras e das informações fornecidas pelas Irmãs em entrevistas, foi possível construir o seguinte organograma da Congregação que assim se estruturava por volta de 1850: 


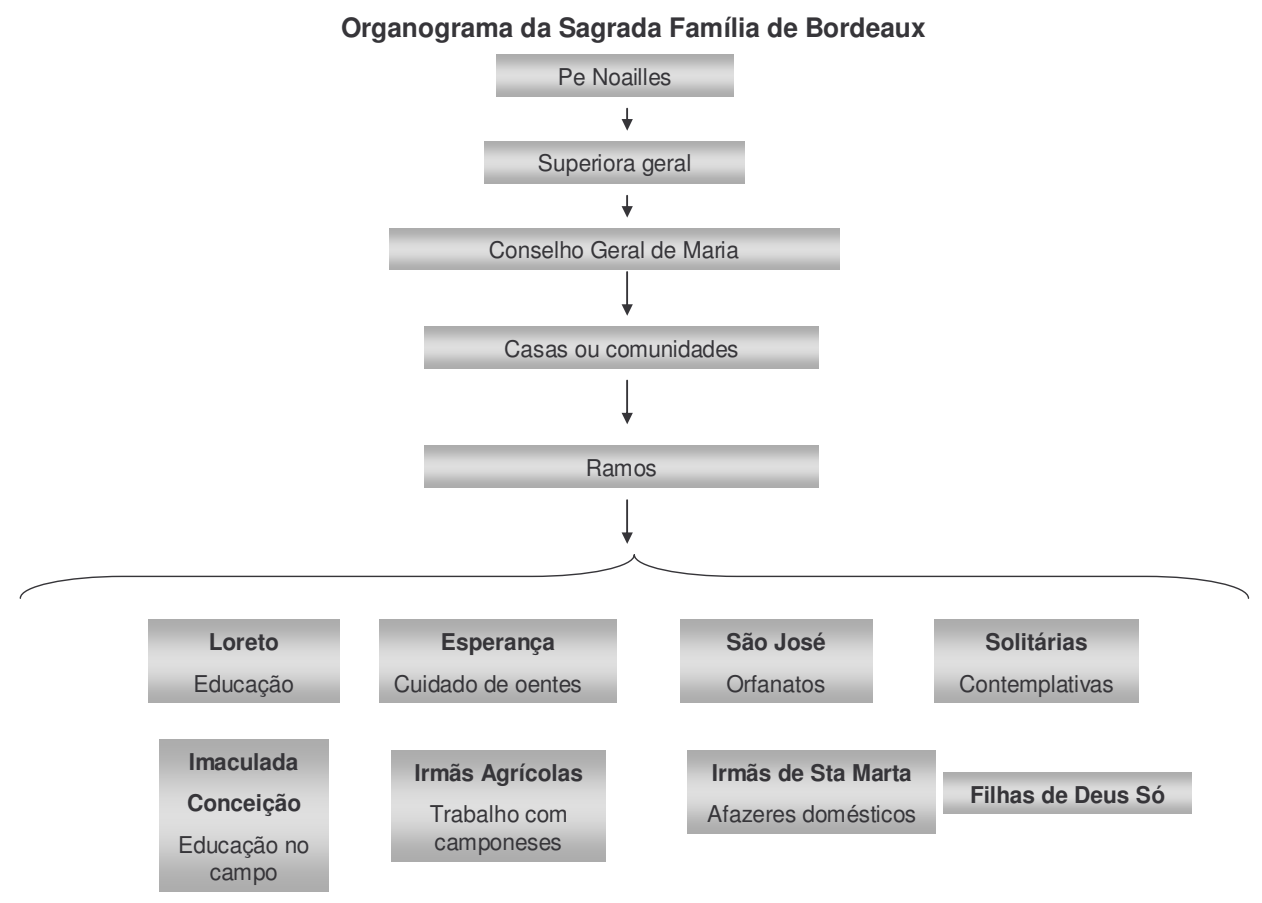

O fundador aparece acima daquela que seria a superiora geral e ambos seriam auxiliados pelo Conselho Geral de Maria, formado por irmãs. Dessa primeira hierarquia, emanavam todas as ordens para as diversas casas ou comunidades que abrigavam irmãs de um dos oito ramos. O ramo de Loreto, por exemplo, era destinado à educação. As irmãs que aí ingressassem se dedicariam à formação de crianças da elite. $\mathrm{O}$ ramo da Esperança era formado por irmãs enfermeiras que se dedicavam ao cuidado de doentes. As irmãs do ramo de São José se dedicavam à educação de crianças pobres e assim sucessivamente. Somente as Filhas de Deus Só, irmãs que abriam mão da escolha por um dos ramos, poderiam ser enviadas para qualquer tipo de trabalho ou missão que lhes indicassem seus superiores.

A Sagrada Família foi uma das Congregações de maior expansão na França, instalada em diversos pontos do país, estruturando-se como uma espécie de empresa (LANGLOIS, 1984). Quando as irmãs partiram para o Brasil, a instituição possuía 85 casas ou comunidades na França ${ }^{14}$. Entre as 25 primeiras congregações em pessoal e em riqueza analisadas por Langlois entre 1878 e 1880, encontra-se a Sagrada Família de Bordeaux em $11^{\circ}$ lugar. Somente até o ano de 1834, os Anais da instituição registraram 49 fundações. À época da fundação no Brasil essa Congregação já havia estendido seus ramos para outros países: Espanha em 1844 (Loreto), Bélgica em 1854 (Esperança), Argélia em 1857 (Esperança), Ceilão em 1862 (Missões Estrangeiras), Roma em 1864 (Missões Estrangeiras), Marilzburg em 1865 (sul da África, Missões Estrangeiras), Inglaterra em 1868 (Imaculada Conceição), Itália em 1870 (Esperança), Irlanda em 1875 (Imaculada Conceição), Canadá em 1901 (Esperança). Essa abertura para o exterior era um fato principalmente das Congregações femininas já bem consolidadas na França, conforme assinalou Langlois (1984, p. 444):

Uma tal situação existia na igreja desde o século XVI, para os homens, em particular com a Companhia de Jesus. Foi preciso esperar o século XIX para ver as congregações femininas com superiora geral 
conhecerem um desenvolvimento semelhante. A internacionalização é, sobretudo, o feito das congregações francesas e de congregações que, à exceção das Filhas de Caridade, não tem braços masculinos que as controlam. ${ }^{15}$

Já para a Congregação das Irmãs de Nossa Senhora do Calvário, seu desenvolvimento na França e os motivos da vinda para o Brasil foram diversos. Um dos biógrafos do fundador narra a situação à época da fundação: No início do século XIX, o clero do Quercy, dizimado pela Revolução, se ergueu acreditando que uma pastoral vocacional se fazia necessária. Os próprios párocos se tornavam professores e preparavam as crianças para o sacerdócio (MAUREL, 1999, p.17).

Conforme DANSETTE (1965), nas primeiras décadas do século XIX, os bispos esforçaram-se por abrir novos seminários sob a direção dos sulpicianos e lazaristas. As escolas paroquiais tinham papel importante no recrutamento, enviando alunos para os novos seminários. Pierre Bonhomme, considerado fundador da Congregação das Irmãs de Nossa Senhora do Calvário, foi uma das crianças que percorreu este caminho. Tanto Bonhomme quanto Noailles, estudaram em seminários destinados à preparação de uma nova geração de padres voltados para a construção do clero ultramontano obediente a Roma.

As Calvarianas, assim como a Sagrada Família, também nasceram da reunião de moças piedosas sob a direção de um padre. Curiosamente, a formação destas irmãs foi feita em outras Congregações já bem estabelecidas em Cahors, cidade próxima a Gramat. Elas eram para lá enviadas e, depois de formadas, retornavam a Gramat para dar continuidade à fundação. Dividindo-se entre diferentes afazeres, Bonhomme não se ocupava totalmente da Congregação nascente como Noailles o fizera. As Calvarianas permaneciam longos períodos sem a presença do fundador que freqüentemente partia em missão deixando a administração por conta das religiosas. As próprias Regras desta Congregação não previam uma estrutura complexa como aquela da Sagrada Família.

Tendo suas origens em uma pequena cidade do sudeste da França, Gramat, a expansão da Nossa Senhora do Calvário foi, sobretudo, na zona rural no oeste e sudoeste da França (cf. STATISTIQUES). Atingida pelas leis de 1901 e de 1903 as irmãs viram a partida para outros países como uma possibilidade de manutenção da instituição.

Deixar as obras do ensino e dedicar-se a outras atividades era uma das soluções encontradas pelas Congregações mistas. Entretanto, a Congregação da Nossa Senhora do Calvário possuía, em 1906, somente $37 \%$ das comunidades dedicando-se a outras tarefas que não o ensino. Nos Relatórios vemos clínicas, hospícios, casas de repouso, atendimento a surdos e doentes mentais, atividades em paróquias, catequese, serviços comunitários e orfanatos. Neste ano, a instituição contava com 511 Irmãs que viviam em 62 comunidades. Como a Congregação havia perdido um grande número de escolas, não havia trabalho para todas as irmãs naquelas escolas que restaram. Dentre as 511 irmãs, 180 não podiam usar o hábito (cf. PLACEMENTS, TABLEAUX ANNUELS, 1869-1933) e lançavam mão de uma secularização fictícia. Algumas dentre elas, com o brevet de professoras poderiam continuar ensinando em escolas públicas desde que secularizadas, isto é, fora das comunidades, renunciando aos votos, deixando a vida religiosa e o hábito. Para isso, deveriam assinar o documento Provas da sinceridade de minha secularização. 


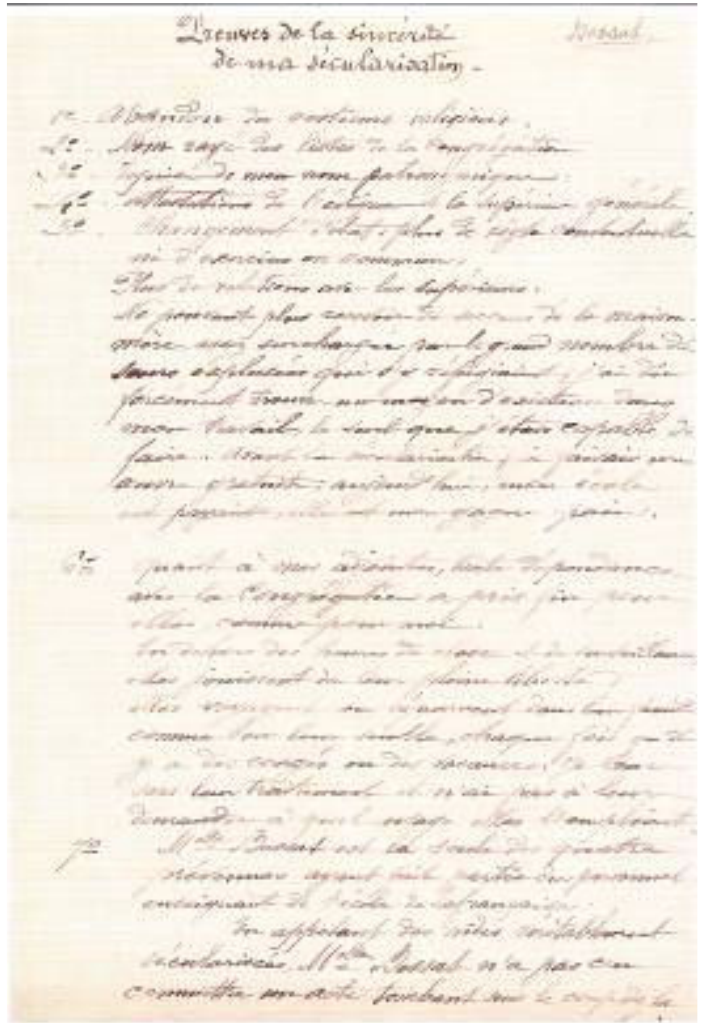

Provas da sinceridade de minha secularização. Não datado e não assinado. Arquivos da Congregação de Nossa Senhora do Calvário, Gramat, França.

Esse documento deveria ser submetido às autoridades para que as irmãs pudessem ensinar nas escolas laicizadas. Assim, elas antecipavam aquilo que ocorreria em meados do século XX: a presença de religiosas e leigos trabalhando em escolas públicas. Entretanto, como já foi mencionado, tratava-se de uma secularização fictícia, ou seja, retirando o hábito religioso, assinando o que fosse necessário para o trabalho em escolas públicas, mas continuando a viver em comunidade e sob os votos. No caso das Calvarianas, cartas trocadas entre as superioras locais e a superiora geral atestam que tal atitude era, muitas vezes, apoiada por pais de alunos.

Além da secularização fictícia na França e daquelas que partiam para suas famílias, outra possibilidade, seguindo os passos de muitas outras Congregações, foi a emigração para países limítrofes (CABANEL \& DURAND, 2005). Em 1904, algumas irmãs Calvarianas foram enviadas para Friburgo (Suíça) para cuidarem da enfermaria e rouparia em um colégio de padres. No entanto, não permaneceram nesse país mais do que um ano. Logo se anunciou, nas circulares emitidas pela superiora, a partida de quatro irmãs para o Brasil. Mas, diferentemente da Sagrada Família, a instalação internacional não era uma característica da Nossa Senhora do Calvário.

Com estruturas diferenciadas, partindo para o Brasil por diferentes motivos, apresentando percursos diversos, a única igualdade em ambas é uma forma de pregação feminina privada que contribuía para a romanização e para a feminização da prática do catolicismo, objetivos da Igreja no período. 


\section{A “pregação" feminina no Brasil}

Para um cristão, pode existir inúmeras formas de reagir às provocações da Providência, Sempre obedecendo- $a$.

$$
(\text { Le Goff })^{16}
$$

As duas instituições vieram para o Brasil a convite de bispos: a Sagrada Família respondeu a um pedido de D. Duarte (arcebispo de São Paulo) feito diretamente ao papa e a Nossa Senhora do Calvário ao convite de D. Nery (então bispo de Pouso Alegre). Mesmo não instalando colégios imediatamente após sua chegada, Dentro das estratégias ultramontanas e da feminização da prática, essas Congregações atuavam em uma forma de educação feminina mais informal e ampliada, evangelizando e educando através de imagens do feminino expostas em cerimônias, nas conversas informais e nas ações e posturas das próprias irmãs.

Nos documentos internos da Nossa Senhora do Calvário, marcados pelas angústias da perda de muitas escolas, a esperança era de poderem desenvolver seu apostolado no Brasil fundando um colégio. $\mathrm{Na}$ crônica intitulada Histoire des fondations brésiliennes, escrita por uma das irmãs que partiu, a narradora mostra ao leitor a superiora dirigindo as seguintes palavras para as irmãs que se dirigiam ao Brasil: "Vocês partem em quatro, eu gostaria que em menos de alguns anos vocês fossem 100”, e se dirigindo a Irmã Pierre du Sauveur (a superiora do grupo que partia para o Brasil), ela acrescentou: "eu conto com você para a fundação de um colégio" (HISTOIRE, v. I, f. 10). ${ }^{17}$ Recrutamento, reprodução local e fundação de um colégio eram as finalidades da instalação das Calvarianas no Brasil.

Já nos Anais da Sagrada Família, figura como objetivo da fundação no Brasil o cuidado de doentes a domicílio (garde malade) como extensão de um dos seus ramos mais numerosos, o ramo da Esperança. Sua partida ao Brasil não respondia somente ao impulso para a missão, mas também tinha como finalidade a expansão internacional.

No entanto, nenhuma das duas congregações alcançou seus objetivos imediatamente. Assim, lançaram mão de outros expedientes para garantirem o sustento da comunidade e, ao mesmo tempo, trabalharem para a política ultramontana via evangelização, para o recrutamento e reprodução local de suas instituições.

No caso da Sagrada Família, nos Anais de 1920 (p. 190) aparece pela primeira vez a menção sobre a fundação no Brasil que, no entanto, já se desenvolvia desde 1908. Somente depois de bem estabelecida, a obra merecia figurar na memória institucional da Congregação e foi assim descrita:

O objetivo da obra foi, antes de tudo, o cuidado de doentes a domicílio. o exercício desse ministério encontrou dificuldades no seio de uma sociedade cosmopolita onde a fé simples do brasileiro é surpreendida e minada pela propaganda de seitas protestantes e pelo liberalismo das classes dirigentes, a neutralidade do ensino oficial, a ignorância popular e a vida fácil das regiões tropicais. Estas dificuldades não amedrontaram as Irmãs missionárias, cujo zelo foi, aliás, solicitado pela visão dos perigos que corriam, neste país, as professoras européias deixadas ao acaso da existência. Proporcionar a esta juventude um abrigo seguro, era procurar, ao mesmo tempo, para a comunidade um local mais amplo que aquele da avenida Angélica. ${ }^{18}$ 
A missão das freiras no Brasil era vista como civilizadora diante de um povo simples, cuja ignorância justificava a própria existência e presença da missionária. Doze anos se passaram até que os Anais divulgassem a história da comunidade, já elaborando o desvio na mudança dos trabalhos do grupo: elas haviam partido para serem gardes malades e acabaram por abrir um pensionato. Instaladas em São Paulo, não conseguiram desenvolver o trabalho de cuidado de doentes encontrando resistências. Conforme relatos de madre Renaux (superiora no Brasil), por um lado, os médicos estavam habituados a cuidar de seus pacientes pessoalmente e hostilizavam as Irmãs. Por outro, as famílias, ao contratarem o serviço das gardes malades, solicitavam que elas também fizessem os serviços de limpeza e cuidados da casa, como domésticas. A superiora assim se expressava em 19 de outubro de 1908:

As irmãs encontram reais dificuldades com alguns doentes onde elas são chamadas para uma ou duas noites somente, os médicos têm o hábito de cuidar eles mesmos de seus doentes e eles estão descontentes com a chegada das Irmãs; diante das famílias, eles não receiam de humilhá-las $e$ de depreciá-las. A vocação da Esperança surpreende e não é bem compreendida. Parece-se lamentar que as irmãs não cuidem das senhoras grávidas, mas a superiora é firme sobre esse ponto ${ }^{19}$.

As Regras não permitiam que as Irmãs atendessem mulheres grávidas e as patronas da obra, as senhoras da família Prado, lamentavam que as irmãs não atendessem gestantes. Aconselhadas pelo bispo a abrirem um pensionato, as irmãs cederam lentamente. No início, evitavam normalistas consideradas jovens levianas (CORRESPONDANCES, 3/2/1909). Dois anos transcorreram com cartas anunciando entrada e saída de pensionistas e o trabalho com doentes acontecendo sempre com dificuldades. Finalmente em 1910, a superiora cedeu e passaram a receber também normalistas. Em 1913, as Irmãs já abrigavam 40 pensionistas na casa e a concorrência preocupava madre Renaux: Parece urgente dar extensão à obra, pois outras Comunidades, vendo o sucesso da Esperança, têm a intenção de também tomar damas pensionistas (CORRESPONDANCES, $25 / 6 / 1911)^{20}$.

Os Anais assinalavam o trabalho do pensionato como uma obra de proteção de jovens. Apagando os aborrecimentos, o problema da concorrência, os preconceitos com relação às normalistas e a mudança na orientação dos trabalhos, eles passavam a narrar, sempre, o grande trabalho realizado pelas Irmãs nas terras brasileiras: a conversão. Essa era a sua pregação no Brasil preparando, ao mesmo tempo, indivíduos aptos, também, a multiplicá-la. O pensionato não só convertia, levando inúmeras jovens à comunhão tardia, como multiplicava as operárias, expressão utilizada nos diferentes documentos: as pensionistas tornavam-se catequistas voluntárias. Em 1920, havia 100 pensionistas na casa e, em 1925 os Anais (p. 291) anunciavam todo o trabalho educativo realizado pelas irmãs:

Além da obra dos Tabernáculos e das Congreganistas que continuam florescendo, duas outras começaram este ano.

As Noelistas escolheram a Casa da Esperança como centro de suas reuniões semanais. Elas aí trabalham com zelo para as crianças pobres. As filhas do Consul da França tomaram a iniciativa desse movimento caritativo que deu origem à uma outra boa obra: as organizações de curso de filosofia dado às jovens da sociedade Paulista, por um padre beneditino. Suas conferências semanais são bastante seguidas, e os bons resultados obtidos são mais encorajadores em um país tão fortemente

Revista HISTEDBR On-line, Campinas, n.34, p.180-198, jun.2009 - ISSN: 1676-2584 191 
trabalhado pelos judeus e seitas protestantes. O espiritismo, sobretudo, faz devastações consideráveis. Quanta ignorância religiosa encontram nossas irmãs no exercício de seu ministério! ${ }^{21}$

As mulheres engajadas nos Tabernáculos dedicavam-se a preparar ornamentos para capelas e igrejas. Aquelas que se ligavam às Filhas de Maria, Apostolado de Oração ou à devoção ao Sagrado Coração de Jesus eram chamadas congreganistas. Todas essas devoções foram estimuladas pelo ultramontanismo no Brasil desde meados da década de 1870 e floresceram, sobretudo, após a proclamação da República (BEOZZO, 1980; NUNES, 1985). Já as conferências, idéia que partiu das filhas do cônsul francês, poderiam ser uma adaptação de cursos leigos criados na França para atender meninas no final do século XIX, conforme ressaltou Mayeur (1977, p. 1 e 2): Os cursos secundários, espécie de sistema de conferências oferecem às suas alunas uma forma pedagógica inédita, leve e sensível às modas, particularmente adaptada à educação de jovens meninas do mundo (....). ${ }^{22}$ Encontram-se aqui, diferentes formas de educar e de transmitir ensinamentos católicos que não através dos colégios ou internatos.

Certamente, a tarefa do cuidado das moças, as atividades no pensionato que envolviam essas jovens favoreciam também a própria reprodução da Congregação no Brasil. Algumas vocações se desenham (... $)^{23}$, escrevia a superiora em 21 de agosto de 1934 propondo à sede que alugassem uma casa para o noviciado.

Desde a chegada das irmãs ao Brasil, algumas postulantes e noviças foram apresentadas nas cartas, mas logo desapareceram. A exigência de realizarem sua formação na França antes que o noviciado no Brasil fosse autorizado dificultava o recrutamento, segundo informava a superiora. O noviciado iniciou-se no Brasil somente em $1942 \mathrm{com}$ a tomada de hábito de duas jovens (cf. REGISTRE ESPÉRANCE, STATISTIQUES, 1942). Mas, mesmo assim, ocorreram desistências. Durante a década de 1950, o número de jovens que entrava para o noviciado variava entre duas e quatro noviças e, também a cada ano, uma delas sempre o deixava. Em 1957, dentre quatro cerimônias de tomada de hábito naquele ano, nenhuma das jovens permaneceu na Congregação. Duas dentre elas deixaram-na no mesmo ano, uma delas saiu no ano seguinte e a outra em 1958. Neste ano, o número de tomada de hábitos cresceu significativamente: foram oito jovens, das quais duas deixaram a Congregação em 1960. Em 1959 e 1960 foram, respectivamente 5 e 4 jovens, sendo que somente uma delas abandonou a comunidade. Em 1961, o número de tomadas de hábito se elevou para 9.

Apesar de deixarem o noviciado, as cartas indicam que as jovens permaneciam próximas às irmãs e, certamente, difundiam a moral católica em suas famílias e redes de relações mais estendidas do que o pensionato e o convento.

Resta examinar, ainda, os percursos da Nossa Senhora do Calvário em terras brasileiras. Ao chegarem em Pouso Alegre, Minas Gerais, as Irmãs deveriam assumir a direção da Santa Casa da cidade, administrada por uma comissão formada por doze homens e da qual o bispo era presidente. O local havia sido comprado pelo major João Basílio e ofertado a D. Nery. 


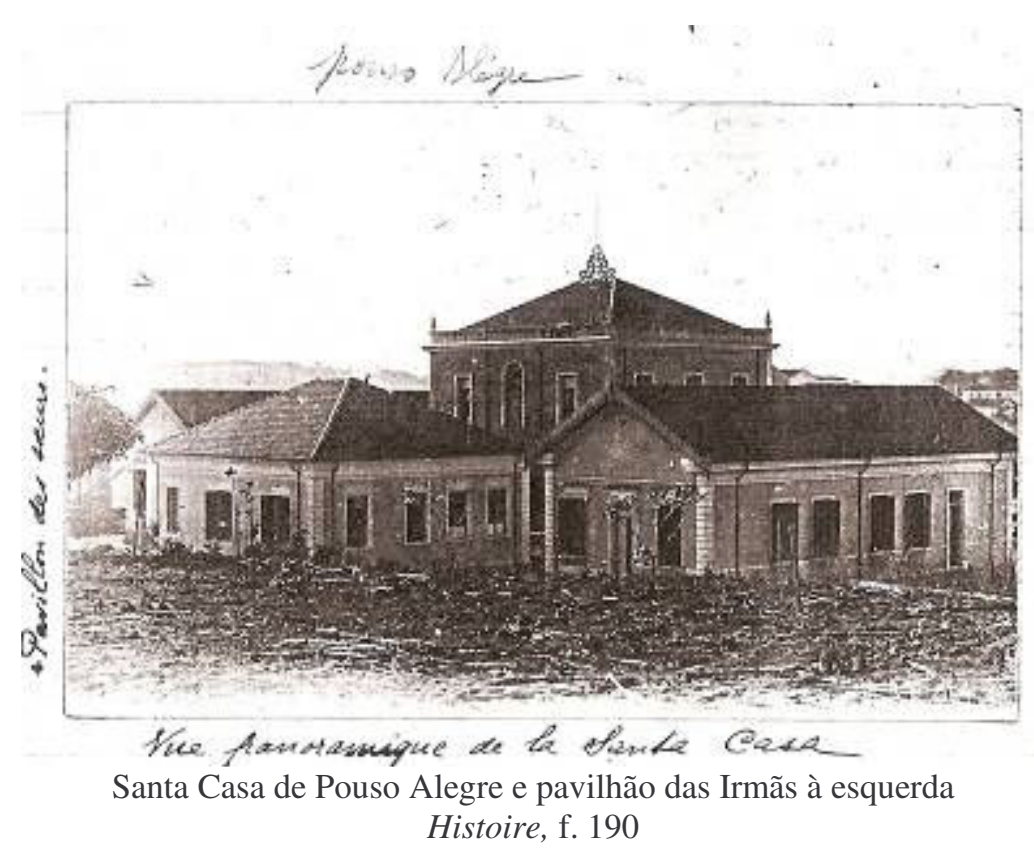

Na foto, colada na Histoire, crônica das irmãs no Brasil, a autora indica o pavilhão das irmãs à esquerda, procurando ilustrar a precariedade do lugar e as dificuldades que passaram nos primeiros tempos vividos na Santa Casa. Três ou quatro dias depois de nossa chegada, dizem as Irmãs, nós vimos que o trabalho não nos vinha, e nós sofremos muito com esta inação (HISTOIRE, v. I, f. 41) ${ }^{24}$.

Ao mesmo tempo em que iniciaram seu trabalho na Santa Casa, ao que parece, precisavam conseguir seu sustento de outras formas. Foi-lhes proposto cuidar da lavagem das roupas das Irmãs Visitandinas, também instaladas na cidade. O mesmo lhes propôs D. Nery para o seminário e colégio da cidade. A cronista da Histoire (v. I, f. 41) afirmava: Esta proposta não era muito para nos encorajar. Havíamos deixado a França para nos fazer lavadeiras? Não, sem dúvida. Mas nós havíamos deixado para nos conformar à vontade de Deus ${ }^{25}$.

Embora tivessem iniciado a catequese com duas crianças e ensaiado aí os primeiros passos para uma escola, seu grande trabalho, no início, era uma espécie de confissão não formal realizada com os doentes e que acabava por encaminhá-los para a posterior conversão com o padre. A cronista narra o trabalho da seguinte forma:

Um outro (doente), obstinado em suas vias perversas, diz francamente à enfermeira que não quer ouvir falar em confissão... Ele foi obedecido nos primeiros dias... mas como isso acontece freqüentemente em hospitais dirigidos por religiosas, os pecados são contados sob a forma de história às enfermeiras, antes de serem narrados ao padre...

Nos interessávamos sobre a vida passada, sobre a família, perguntando sobre isso e, como é um dos lados fracos do homem como da mulher, de amar falar de si, esses pobres doentes, o mais naturalmente, contavam toda sua vida (HISTOIRE, v. I, f. 142) ${ }^{26}$.

A respeito deste doente, afirmou a cronista que Deus trabalhou bem sua alma e ele mesmo pediu um padre para se confessar alguns dias depois. Muito mais próximas das pessoas que os próprios padres, longe da severidade e do ritual do confessionário, elas escutavam muito mais e pregavam à sua maneira, pela catequese e por uma espécie de 
confissão informal. Da mesma forma que na Sagrada Família, as irmãs Calvarianas trabalhavam na sombra para a implementação da política ultramontana.

O plano de ação da Igreja no período, segundo a orientação ultramontana, visava à expansão dos quadros, de frentes de trabalho pastoral (especialmente a catequese) e dos sacramentos. Para esses últimos, a figura do padre era indispensável. Mas, eram as freiras que encaminhavam as pessoas até os padres. Elas podiam fazer uso da palavra para a conversão em espaços privados, especialmente entre mulheres que são a maioria nos relatos de conversão realizados por elas, trabalhando para o projeto reformador da Igreja, difundindo e fortalecendo os valores femininos na família, objetivo último desta política conforme ressaltou NUNES (1996). Nas duas congregações aqui apresentadas variadas formas de educação e evangelização concorriam para isso. Dessa forma, elas também recrutavam para o trabalho pastoral e para a formação dos quadros das próprias congregações.

Assim como na Sagrada Família, as primeiras aspirantes das Calvarianas apareceram logo nos primeiros anos de instalação da Congregação no Brasil. Em circular de 18/12/1908, anunciava-se que a primeira aspirante de Pouso Alegre foi admitida à tomada de hábito. Em 1908, D. Nery foi nomeado bispo da diocese de Campinas, São Paulo, e solicitou às Irmãs de Nossa Senhora do Calvário que partissem com ele para tentarem abrir um colégio nessa cidade. Depois de partir com as Irmãs para o recém fundado Colégio de Campinas, a narradora informa que a noviça foi enviada para Pouso Alegre e, em seguida, para sua família já que apresentou uma mentalidade desequilibrada $\left(\right.$ HISTOIRE, v. I, f. 139) ${ }^{27}$. Provavelmente conflitos culturais influenciaram a saída do noviciado. Outra jovem postulante entrou para o noviciado e tomou o hábito em 1911, mas sua história também foi esquecida ao longo da Histoire.

Além do recrutamento via cuidado de doentes, a cronista informava os resultados do trabalho no Colégio de Campinas para o ano de 1913: Três ou quatro de nossas melhores alunas cultivam o desejo de entrar conosco, e esperam o momento propício para obter o consentimento de seus pais. É deles que surgirá toda a dificuldade (HISTOIRE, v. I, f. 144$)^{28}$. Em 1914, anunciaram-se mais duas postulantes e a tomada de hábito de duas noviças. Embora o Colégio criasse as condições para despertar o desejo de entrada para a vida religiosa, poucas permaneciam ou levavam adiante esse projeto. Somente em 1918, entra a primeira jovem recrutada no Colégio.

Assim como na Sagrada Família, mesmo abandonando o projeto de entrada para a Congregação, certamente estas jovens também estavam aptas a reproduzir a moral e a difundir o catolicismo em suas famílias.

\section{Considerações finais}

Ainda que existissem diferenças significativas nas estruturas das duas Congregações aqui analisadas, ambas encontraram formas de pregar e de trabalhar para o catolicismo ultramontano evangelizando e educando. Tanto as Calvarianas quanto as irmãs da Sagrada Família vieram para o Brasil pretendendo desenvolver trabalhos que não aconteceram imediatamente. Para a Sagrada Família de Bordeaux, o trabalho de cuidado de doentes a domicílio (gardes malades), que não era bem compreendido no novo país e contava com a hostilidade dos médicos, demorou a frutificar. Enquanto isso, as Irmãs abriram um pensionato para professoras e normalistas que, ao que tudo indica, tornou-se sua principal fonte de renda. Para a Nossa Senhora do Calvário, o objetivo da vinda era a fundação de um colégio. Entretanto, as Irmãs passaram um ano em Minas Gerais cuidando 
de uma Santa Casa e de um seminário até sua partida para Campinas, onde o colégio foi fundado. Tanto uma quanto a outra, ao trabalharem com a educação não formal, oferecendo cursos para as damas pensionistas ou catequisando e convertendo doentes, contribuíam para a feminização da prática do catolicismo visada pela política ultramontana em vigor no país, ao mesmo tempo em que recrutavam mulheres para seus quadros. Ou seja, mesmo sem os colégios, educavam mulheres para uma visão de mundo e lugar social específicos.

Essas duas instituições inserem-se no quadro de mudanças processadas no Brasil, na França e na Igreja de um modo geral na segunda metade do século XIX. A grande entrada de congregações femininas no Brasil no período e sua ação na educação não formal ainda estão por ser explorados. Observar e analisar a educação feminina fornecida por congregações religiosas implica em conhecer melhor as condições de fundação dessas congregações, inseridas ou não no movimento de feminização do catolicismo, conhecer suas posições no interior da Igreja para compreender sua ação no campo educacional no Brasil. Outras pesquisas poderiam estender as questões aqui levantadas e acrescentar novas para o caso de outras instituições, valorizando um olhar por dentro através de documentos internos e colocando em comparação a situação de congregações femininas e masculinas.

\section{Referências bibliográficas}

\section{Fontes}

1.1. Sagrada Família de Bordeaux

SAINTE FAMILLE DE BORDEAUX. Règles générales des associées de la Sainte-Famille, Introduction. Bordeaux, Imprimerie de Th. Lafargue, Libraire, 1851, p. 51. Nas citações seguintes farei referência ao documento somente como Introduction.

Iimprimerie de Th. Lafargue, Libraire, 1851.

Régles générales des associés de la Sainte Famille. Bordeaux : Statistiques, Archives de la Sainte Famille de Bordeaux.

\subsection{Nossa Senhora do Calvário}

MAUREL, Cônego P. Presença do jeito de Maria no Calvário. Congregação das Irmãs de Nossa Senhora do Calvário de Gramat: desde suas origens, 1833, até 1900. São Paulo: Edições Loyola, 1999.

Histoire des fondations brésiliennes. 1916. Manuscrito.

Placements. Tableaux Annuels - 1869 - 1933.

\section{Bibliografia}

AZZI, Riolando (org). A vida religiosa no Brasil. Enfoques históricos. São Paulo: Editora Paulinas, 1983.

BEOZZO, José Oscar et all. História da Igreja no Brasil. Ensaio de interpretação a partir do povo. Petrópolis, RJ: Editora Vozes, 1980.

BOURDIEU, Pierre. A economia das trocas simbólicas. São Paulo: Editora Perspectiva, 1999.

CABANEL, Patrick e DURAND, Jean-Dominique. Le grand exil des congrégations religieuses françaises. 1901-1914. Paris : Les Éditions du CERF, 2005.

CHAGAS, Alessandra Pereira da Silva \& ROSSI, Michelle Pereira da Silva. Formação da mulher republicana no oeste do Brasil: avante professoras!. VIII Seminário Nacional de Estudos e Pesquisas Histedbr, História, Educação e Transformação: tendências e perspectivas. Universidade Estadual de 
Campinas, 2009. Disponível em: www.histedbr.fae.unicamp.br/acer_histedbr/.../3D2f7rF.doc, 10 de agosto de 2009, 20 h46.

DALLABRIDA, Norberto. A fabricação escolar das elites. O Ginásio Catarinense na Primeira República. Florianópolis, SC: Cidade Futura/UDESC, 2001.

DANSETTE, Adrian. Histoire religieuse de la France contemporaine. L'Église catholique dans la mêlée politique et sociale. Paris : Flammarion, 1965.

LANGLOIS, Claude. «Le catholicisme au féminin revisité. In : CORBIN, Alain, LALOUETTE, Jacqueline, RIOT-SARCEY, Michèle (dir). Femmes dans la cité (1815-1871). Grâne, Éditions Créaphis, 1992.

Le catholicisme au féminin. Les congrégations françaises à supérieure générale au XIXe siècle. Paris : Les Editions du Cerf, 1984.

LA BELLA, Gianni. L'éxil dês religieux de France, 1901-1904: l'arrivée en Amérique Latine. In : CABANEL, Patrick e DURAND, Jean-Dominique. Le grand exil des congrégations religieuses françaises. 1901-1914. Paris : Les Éditions du CERF, 2005.

LE GOFF, Jacques. Saint Louis. Paris : Gallimard, 1996.

LEONARDI, Paula. Puríssimo Coração: um colégio de elite e sua imagem. Pró-Posições, v. 15, n. 2 (44), Campinas, 2004.

Além dos espelhos. Memórias, imagens e trabalhos de duas Congregações católicas francesas no Brasil. São Paulo, Tese de doutorado, Faculdade de Educação/Usp, 2008.

. Education and recruitment in French Catholic Congregations in Brazil: gender subjects. ISCHE 31 - International Standing Conference for the History of Education, august 2009, Utrecht.

MANGION, Carmen M. Contested identities. Catholic women religious in nineteenth-century England and Wales. Manchester: Manchester University Press, 2008.

MAYEUR, Françoise. L'enseignement secondaire des jeunes filles sous la Troisième République. Paris : Presses de la Fondation Nationale de Sciences Politiques, 1977.

MANOEL, Ivan A. Igreja e educação feminina (1859-1919): uma face do conservadorismo. São Paulo: Editora da Unesp, 1996.

MICELI, Sérgio. A elite eclesiástica brasileira. Rio de Janeiro: Bertrand Brasil, 1988.

MOURA, Laércio. A educação católica no Brasil. São Paulo, Edições Loyola, 2000.

NUNES, Maria José. Freiras no Brasil. In: DEL PRIORE, Mary. História das mulheres no Brasil. São Paulo: Contexto, 1997.

PEROSA, Graziela S. Três escolas para meninas. Tese de doutorado. Faculdade de Educação, Unicamp, Campinas, 2005.

ROSSI, Michelle Pereira da Silva \& INÁCIO FILHO, Geraldo. As congregações católicas e a disseminação de escolas femininas no Triângulo Mineiro e Alto Paranaíba. Revista Histedbr on line, Campinas, n. 24, p. 79 - 92, dez 2006.

ROUX, Rodolpho. De la nation catholique à la republique pluriculturelle en Amerique Latine. In: ROUX, Rodolpho (org). De l'un au multiple. Dynamiques identitaires en Amerique Latine, Tolouse, Presses Universitaires du Mirail, 2008.

VILLARES, Artur. As congregações religiosas em Portugal. (1901-1926). Lisboa: Fundação Calouste Gulbenkian, Fundação para a Ciência e a Tecnologia, 2003. 
${ }^{1}$ Este artigo apresenta fontes e informações coletadas também durante minha pesquisa de doutorado que
contou com o financiamento da CAPES. Algumas questões se desenvolveram a partir de discussões com os
integrantes do GEHER (Grupo de Estudos sobre História da Educação e Religião).
${ }^{2}$ Pós-doutoranda em História e Historiografia da Educação, Faculdade de Educação USP.
${ }^{3}$ No caso deste grupo, a casa onde viviam foi apedrejada.
${ }^{4}$ A expressão é utilizada no interior da Igreja para designar a missão aos povos. A Congregatio Propaganda
Fide, ou Congregação para a Evangelização dos Povos foi fundada em 1622 para coordenar toda a atividade
missionária da Igreja e propagar a fé católica em todo o mundo. Dentre suas atividades está a
responsabilidade pela aprovação das congregações e promover a formação do clero. A nova Congregação
torna-se, deste modo, o instrumento ordinário e exclusivo do Santo Padre e da Santa Sé, para o exercício de
jurisdição sobre todas as missôes e cooperação missionária. Disponível em
http://www.fides.org/por/congregazione/storia.html, 12 de agosto de 2009, 21 h45. 5 Há notícias de grande entrada de mulheres para vida religiosa durante o século XIX na França (LANGLOIS, 1986), Portugal (VILLARES, 2003), Inglaterra e País de Gales (MANGION, 2008).

${ }^{6}$ A idéia do mapa leva em conta que Azzi (1983) já havia apontado o aumento na entrada de Congregações estrangeiras no país, sem, no entanto, construir um quadro relacional da entrada de Congregações masculinas e femininas.

${ }^{7}$ Entende-se, aqui, evangelização como educação que se volte para o Evangelho. A educação católica tem como fim a evangelização, a difusão do Evangelho, que resultaria em comportamentos e práticas específicos. Na perspectiva da Igreja, portanto, educação é evangelização. É dessa forma que o termo será utilizado neste artigo.

${ }^{8}$ Femininas em São Paulo: Congregação das Irmãs de São José de Chambéry, Congregação de Nossa Senhora da Caridade do Bom Pastor de Angers, Congregação das Irmãs Missionárias de São Carlos Borromeu, Congregação das Pequenas Irmãs da Divina Providência, Congregação das Missionárias Zeladoras do Sagrado Coração de Jesus, Congregação das Missionárias do Sagrado Coração de Jesus, União das Cônegas Regulares de Santo Agostinho da Congregação de Nossa Senhora, Congregação das Irmãs Franciscanas Missionárias do Coração Imaculado de Maria, Congregação da Sagrada Família de Bordéus, Monjas da Ordem de São Bento, Congregação das Filhas de Jesus, Congregação de Santa Catarina de Sena da Ordem Terceira de São Domingos, Congregação das Servas do Santíssimo Sacramento, Congregação das Irmãs de Santa Marcelina.

Masculinas em São Paulo: Congregação do Espírito Santo e do Imaculado Coração de Maria, Pia Sociedade dos Missionários de São Carlos, Congregação dos Missionários Filhos do Imaculado Coração de Maria, Ordem Premonstratense, Congregação dos Missionários de Nossa Senhora da Salette, Congregação da Santíssima Cruz e Paixão de Nosso Senhor Jesus Cristo, Congregação dos Padres de Nossa Senhora de Sion.

${ }^{9} \mathrm{O}$ estatuto jurídico dessas instituições no interior da Igreja podia ser de direito pontifício ou diocesano. Ou seja, podiam ser submetidas diretamente ao papa, como também acontecia com as ordens, ou submetidas ao bispo. Fundamentalmente, o que difere congregação de ordem para Langlois (1988) é que as religiosas que vivem nas primeiras podiam professar somente votos simples (temporários), tinham as casas ligadas a uma casa mãe e tinham vida ativa. As ordens mantinham a independência de governo e administração em cada uma de suas casas, não se submetendo a uma administração centralizada e tinham vida mais reclusa, menos presente em espaços públicos e professavam votos solenes (perpétuos). Embora a novidade do século XIX seja a expansão crescente do modelo congregacionista, a tradição de algumas ordens conferiam a seus membros status elevado no interior da Igreja, o que podia resultar em alianças com grupos de elite e dirigentes, como se verá adiante. Além disso, a vida religiosa nas congregações do século XIX podia ser vista por muitas mulheres como uma vida de menor perfeição, conforme observou Mangion (2008) e Leonardi (2008).

${ }^{10}$ Jules Ferry foi nomeado várias vezes ministro da Instrução Pública na França e promoveu reformas que visavam afastar a Igreja Católica da Educação. Suas idéias e propostas foram gestadas e alimentadas em meio ao clima geral secularizante que se aprofundava na França desde a Revolução Francesa. Para aprofundamento: Mayer (1977), Dansette (1965) e Boyer (2005) Aspects juridiques des lois de 1901 et de 1904 sur les congrégations, in Cabanel \& Durand, op.cit.

${ }^{11}$ Embora no caso do primeiro colégio trate-se de uma Congregação austríaca, nesse país essas instituições viveram situação semelhante à da França.

${ }^{12}$ http://www.sfb.pcn.net/projet, acessado em 1/11/2007, $16 \mathrm{~h} 19$.

${ }^{13}$ Congregação e associação leiga diferiam, portanto, não pela atividade que exerciam (ensino ou cuidado de doentes), mas pela vida comunitária assumida pela primeira, por receberem uma regra de vida (dada pelo bispo) e por possuírem os atributos da comunidade (noviciado permitindo recrutamento) e poder (Casa Mãe com uma superiora geral). 
${ }^{14}$ As comunidades estavam assim divididas: São José - 2 casas; Loreto - 4 casas; Solitárias - 1; Comunidade de Martillac - 1; Imaculada Conceição - 44 casas; Esperança - 31 casas, dentre as quais uma abrigava também Irmãs de Santa Marta; Agrícolas - 1; Santa Marta - 1. Statistiques, Archives de la Sainte Famille de Bordeaux.

${ }^{15}$ Une telle situation existait dans l'Église, dès le XVIe siècle, pour les hommes, en particulier avec la Compagnie de Jésus. Il faut attendre le XIXe siècle pour voir des congrégations féminines à supérieure générale connaître un développement semblable. L'internationalisation est surtout le fait de congrégations françaises et de congrégations qui, à l'exception des Filles de la Charité, n'ont pas de branches masculines qui les contrôlent. Para os trechos em francês, procedi a livre tradução.

${ }^{16}$ Pour un chrétien, il peut exister plusieurs façons de réagir aux provocations de la Providence tout en lui obéissant. 1996, p. 18.

17 «Vous partez 4, je voudrais qu'en moins de quelques années, vous fussiez 100 », et se tournant vers $S$. Pierre du Sauveur, elle ajouta «Je compte sur vous pour la fondation d'un pensionnat ».

${ }^{18}$ Le but de l'oeuvre avait été, tout d'abord, le soin des malades à domicile. L'exercice de ce ministère rencontra des difficultés au sein d'une société cosmopolite où la foi simple du Brésilien est surprise et sapée par la propagande des sectes protestantes et le libéralisme des classes dirigeantes, la neutralité de l'enseignement officiel, l'ignorance populaire et la vie facile des régions tropicales. Ces difficultés n'effrayèrent pas les soeurs missionnaires dont le zèle fut d'ailleurs sollicité par la vue des périls que couraient, dans ce pays, les institutrices européennes livrées aux hasards de l'existence. Procurer à cette jeunesse un aile sûr, c'était chercher, en même temps, pour la communauté un local plus vaste que celui de la Via Angélica.

${ }^{19}$ Les soeurs rencontrent de réelles difficultés les quelques gardes où elles sont appelées pour un où deux nuits seulement, les médecins ont l'habitude de soigner eux-mêmes leurs malades et ils sont mécontent de l'arrivée des soeurs; devant les familles, ils ne craignent pas de les humilier et de les déprécier. La vocation de l'Esperance étonne et n'est pas bien comprise. On semble regretter que les soeurs ne soignent pas les Dames en couches, mais la supérieure est ferme sur ce point.

${ }^{20}$ Il semble urgent de donner de l'extension à l'oeuvre, car d'autres Ctes voyant la réussite de l'Esperance, ont l'intention de prendre aussi des dames pensionnaires.

${ }^{21}$ En plus de l'oeuvre des Tabernacles et des Congréganistes qui demeurent florissantes, deux autres ont commencé cette année. Les Noëlistes ont choisi la Maison de l'Espérance comme centre de leurs réunions hebdomadaires. Elles y travaillent avec zèle pour les enfants pauvres. Les filles du Consul de France ont pris l'initiative de ce mouvement charitable qui a donné naissance à une autre bonne oeuvre: l'organisations de cours de philosophie donnés aux jeunes filles de la société Pauliste, par un Père Bénédictin. Ses conférences hebdomadaires sont très suivies, et les bons résultats obtenus sont des plus encourageants dans un pays si fort travaillé par les juifs et les sectes protestantes. Le spiritisme, surtout, fait des ravages considérables. Que d'ignorance religieuse rencontrent nos Soeurs dans l'exercice de leur ministère!

${ }^{22}$ Les cours secondaires, sorte de systèmes de conférences crées offrent à leurs élèves une forme pédagogique inédite, souple et sensible aux modes, particulièrement adaptée à l'éducation des jeunes filles du monde (...).

${ }^{23}$ Quelques vocations se dessinent (...).

${ }^{24}$ Trois ou quatre jours après notre arrivée, disent les soeurs, nous vîmes que le travail ne venait pas à nous, et nous souffrimes pas mal de cette inaction.

${ }^{25}$ Cette proposition n'était guère faite pour nous encourager. Avions-nous quitté la France pour nous faire lavandière? Non, sans doute. Mais nous l'avions laissée pour nous conformer à la volonté de Dieu.

${ }^{26}$ Un autre, obstiné dans ses voies perverses, dit très carrément à l'infirmière qu'il ne voulait pas entendre parler de confession... Il fut obéi les permiers jours... mais comme cela arrivé souvent dans les hôpitaux dirigés par des religieuses, les pechés étaient racontés sous forme d'histoire aux infirmières, avant d'être narrés au prêtre... On s'intéressait sur la vie passée, sur la famille, en questionnait, et comme c'ést un des côtés faibles de l'homme, comme de la femme, d'aimer à parler de soi, ces pauvres malades, le plus naturellement du monde, contaient toute leur vie.

27 A frase, na íntegra, é a seguinte: La jeune novice avait donné des signes alarmants d'une mentalité déséquilibrée.

${ }^{28}$ Trois ou quatre de nos meilleures élèves cultivent le désir d'entrer chez nous, et attendent le moment propice pour obtenir le consentement des parents. C'est d'eux qui surgira toute la difficulté.

Artigo recebido em: 25/4/2008

Aprovado para publicação em: 31/08/09 